\title{
Ultra-Low-Level Laser Stimulation of LU7 Lieque Promotes Breath Functionality: Could it be of help in Covid 19 Rehabilitation? - A Multiple Case Report
}

\author{
Marzio Vanzini ${ }^{1}$, Daniele Gullà ${ }^{2}$, Michele Gallamini ${ }^{* 3}$ \\ ${ }^{1}$ (MV), Acupuncturist, Ophthalmologist - Oculistica Viva Clinic Bologna Italy; \\ https://orcid.org/0000-0002-8489-9441 \\ ${ }^{2}$ (DG) Founder and CEO of Hyperspectral Imaging Co; Consultant to CNR Bologna \\ ${ }^{3}$ (MG) Medical Devices Freelance Researcher Sal. Maggiolo di Nervi, 716167 Genoa, Italy; \\ https://orcid.org/0000-0002-4550-526X
}

*Corresponding author: Michele Gallamini; michele.gallamini@fastwebnet.it

Received 22 February 2021;

Accepted 08 March 2021;

Published 17 March 2021

\begin{abstract}
The burden of post COVID rehabilitation is and will be a strong concern for healthcare stakeholders. The Traditional Chinese Medicine is suggesting the application of acupuncture as a dependable tool to be inserted in the rehabilitation project. Libralux, an ultra-low-level-laser stimulator has proven its effectiveness as acupuncture stimulator. In this paper we report the respiratory cycle modifications obtained through the stimulation with Libralux of the acupoint LU7 LieQue of three healthy individuals. Modifications were observed instrumentally by means of an innovative high-resolution camera plotting the chest expansion vs. time. The results demonstrate a remarkable increase in respiration depth and in the contemporary reduction of the respiration frequency within 20 minutes from the $20 \mathrm{sec}$ bilateral stimulation of LU7 LieQue acupoint. The worthiness of a specific full double-blind trial is suggested also in view of the marginal contra-indications, the rapid execution and, most of all, the great potential benefit of the inclusion of a laser acupunctural stimulation in the post COVID rehabilitation project.
\end{abstract}

Keywords: Acupuncture, Laser-acupuncture, Covid 19 rehabilitation, Respiratory efficiency

\section{Introduction}

COVID 19 pandemics is leaving behind the acute phase a great quantity of functional deficits requiring rehabilitation ${ }^{[1,2]}$.

Rather obviously, among the suggestions for rehab, emphasis has been given to several interventions to restore effective respiration. Among them also the application of acupuncture has been suggested.

In previous papers we described the surprising effectiveness of the stimulation of acupoints ${ }^{[3,4]}$, by means of a patented specific pulsed laser operating at ultra-low-power/energy, beyond musculoskeletal conditions ${ }^{[5]}$ also in specific ophthalmological symptomatologies such as amblyopia ${ }^{[6]}$ and the eye blood perfusion in Wide Angle Glaucoma ${ }^{[7]}$.

Efficacy of this peculiar stimulation has been demonstrated on animal models ${ }^{[8-10]}$, and, while trying to understand its action mechanism, on cellular models ${ }^{[11,12]}$. Further studies did suggest a possible action mechanism involving the Extra Cellular soft tissue Matrix (ECM) ${ }^{[13-16]}$.
In view of possible application in Covid 19 Rehabilitation we decided to test the effects of the stimulation of the LU7 LieQue Acupoint.

Main purpose of the present paper is the description of the observed effects on breathing performances of healthy subjects using an un-invasive method using a special camera capable of measuring the chest movements during the breath cycle.

\section{Materials and Methods}

\section{Volunteers}

Three healthy subjects (MV1, MV2, CP) volunteered to be bilaterally treated on the LieQue acupoint with Libralux (Fremslife - Genoa - Italy).

\section{Libralux}

The internationally patented device is endowed with the following main characteristics 
- Laser emission wavelength $650 \mathrm{~nm}$ (visible red emission)

- Peak radiated power $7 \mathrm{~mW}$

- $\quad$ Spot size $10 \mathrm{~mm}^{2}$

- $\quad$ Radiance (Peak) $0.7 \mathrm{mw} / \mathrm{mm}^{2}$

- Total modulation Duty Cycle $0.25 \%$

- Mean radiated power $17.5 \mathrm{uW}$

- Mean Radiance $1.75 \mathrm{uW} / \mathrm{mm}^{2}$

- Stimulation time $20 \mathrm{sec}$

- Administered energy $35 \mathrm{uJ}$ per each point

- Administered energy density $3.5 \mathrm{uJ} / \mathrm{mm}^{2}$
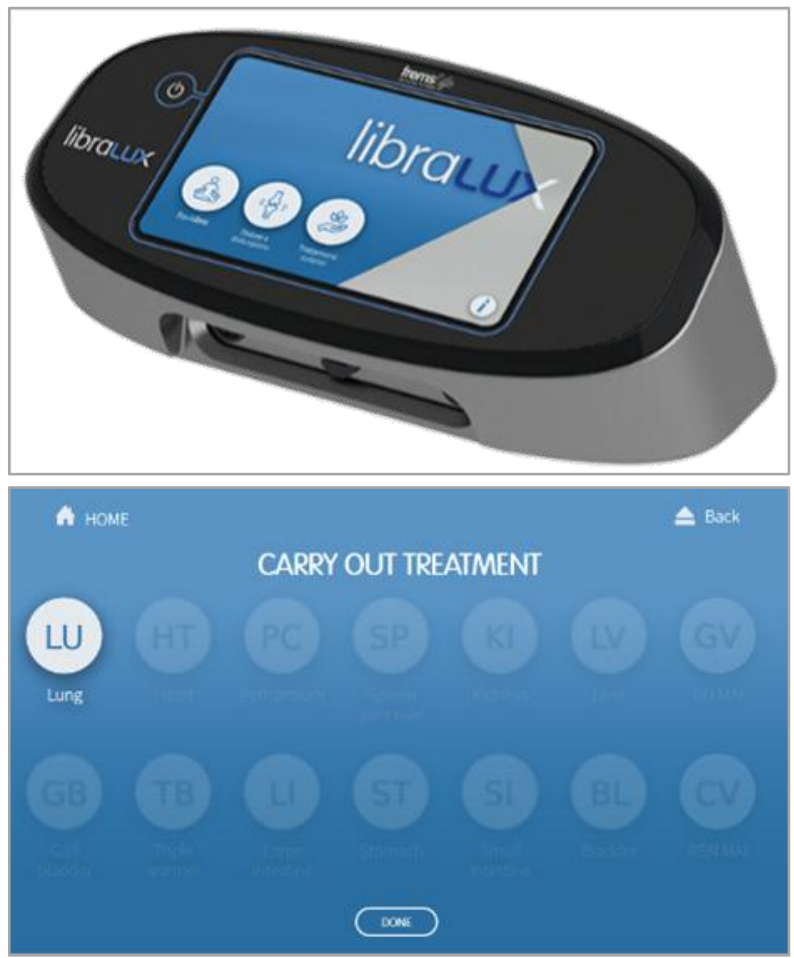

Figure 1: Libralux device and its "meridian stimulation selection page"

The emission/application levels are well under the ones that, according to the most credited sources ${ }^{[17]}$, might produce any biological effect. The effectiveness is probably due to the combination of modulations capable of eliciting biological responses travelling along the acupuncture meridians in the ECM /Fascia substrate ${ }^{[18]}$.

Its square wave modulations are obtained by the logical product among:
- A "Carrier" Frequency $100 \mathrm{~Hz}$

Duty Cycle $1 \%$

- A "Meridian"

Frequencies (12

values 5.5 through

$11 \mathrm{~Hz})$

- A "Antiaddiction" [19]
Duty Cycle 50\%

Duty Cycle 50\%

\section{MIRA Camera}

The functionality of respiration was measured with MIRA (Hyperspectral Imaging Srl - Bologna - Italy): a digital camera HIS capable to provide affordable solutions to vision recording problems so far solved by expensive solutions. MIRA strongholds are in fact a great image processing performance with extremely low power consumption (batteries/solar cells), small size and a limited cost.
The device can record, process, save images and communicate with remote stations exploiting three main functions:

1. Image acquisition by means of low power consumption CMOS sensors endowed with high sensitivity and resolution over the whole band from the near UV to the near IR but can also use hyper-spectral CMOS sensors;

2. Great Image Processing capabilities thanks to a powerful DSP (Digital Signal Processor) capable of over 800 MIPS and with a 64Mbytes SDRAM work memory and a NAND of 8 GBytes;

3. Utter flexibility in data recording and great computing capabilities to measure micromovements (as needed to process face expressions) or perform more usual tasks as Shape Analysis, Tracking, Dynamic Analysis, Vector analysis, Distance measurements, Vibrational analysis, Delta pixel analysis, Interferometer analysis, Differential biophoton analyser, Polarimetry analysis, etc.

MIRA can collect several frames and quickly compare them pixel by pixel: whenever just a few ADU differences are observed the system amplifies this weak signal through complex algorithms (pyramidal FFT) giving colour to monochrome areas according to a pre-set colour code table: This allows to exponentially amplify the electromagnetic field and the photon flux. The last being un-stable and depending on micro-variations and oscillations of optical field luminance and chrominance that are probably of quantum nature.

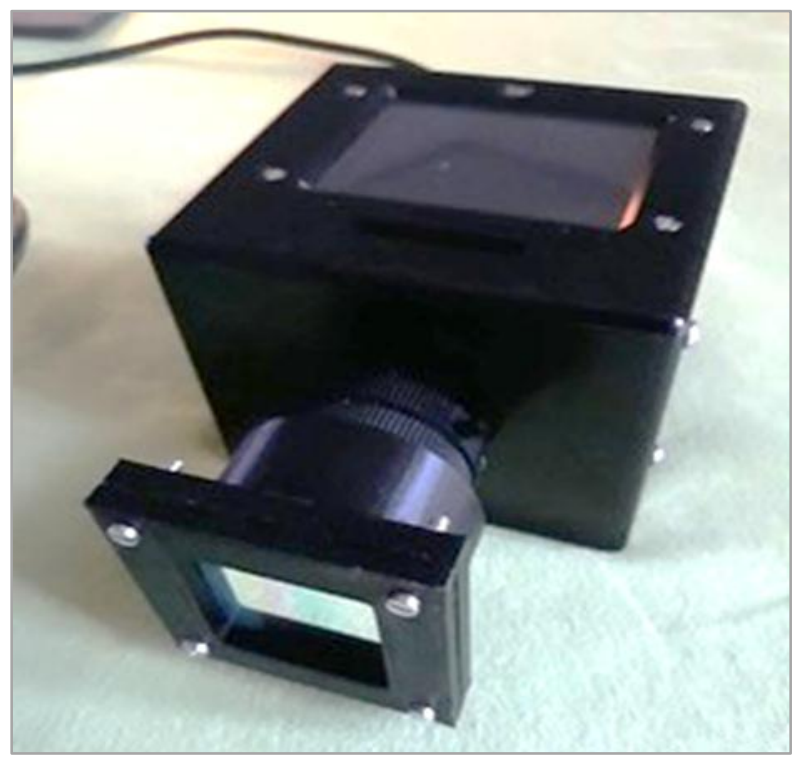

Figure 2: The MIRA camera device

\section{Measurement sequence}

For each individual 4 measurements were performed:

- Just before treatment

- 5 min after treatment

- 20 min after treatment

- 60 min after treatment

\section{The acupuncture stimulation}

The LU7 LieQue is of great importance in Traditional Chinese Medicine applications ${ }^{[20,21]}$. It is the Luo opening point of the Ren Mai, the extraordinary Meridian governing all the yin meridians. It can be stimulated to nourish the yin energy of the whole body and lower the symptoms of Kidneys yin deficit in heat or emptiness syndrome ${ }^{[22-24]}$. 


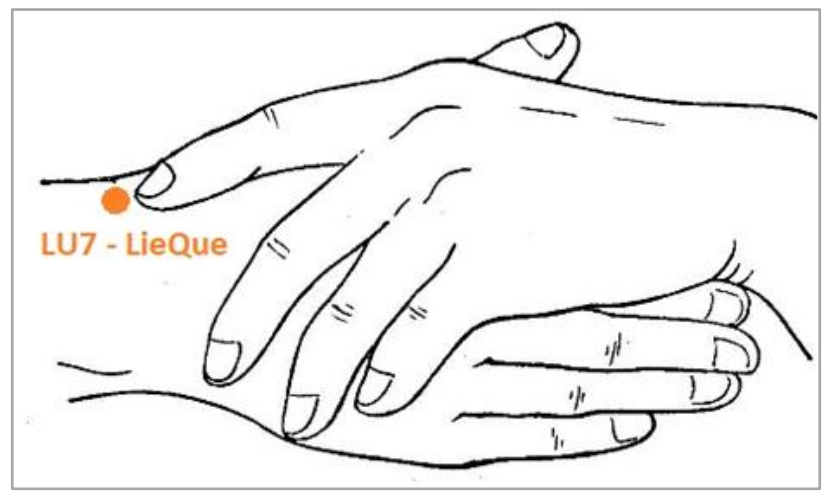

Figure 3: LU7 LieQue

Its stimulation is recommended for externally originated pathologies, acute and in the excess and out-bound movements syndromes. It opens water passages. As so it promotes the descent and the diffusion of Lungs qi with befits for cough and asthma. It dissolves the Phlegm causing the descent of qi and stimulates the defensive qi (weiqi) circulation. Finally, it frees from the cold wind invasions or of the external Heat-Wind. Due to the all above reasons the stimulation of LieQue is indicated to effectively treat Covid-19 infection. Worth remarking that the Lu9 Taiyuan, a tonification point indicated to treat chronic conditions, is less appropriate and does not open water passages.

\section{Results}

As shown in Figure 4, by the raw graph of the thorax excursion (MV1 Subject) the amplitude grows and the frequency of the respiration decreases. The most relevant effect can be noticed at some 20 minutes after the stimulation.

Worth noticing that breathing anomalies - probably slight spasms demonstrated by the automatic signal analysis (vertical blue and pink interrupted lines) - are much more evident immediately after the stimulation but are disappearing $5 \mathrm{~min}$ after treatment. The couples of vertical dotted lines limit the anomaly between its start, shown by the pink line and its stop, shown by the light blue line.

To enhance the visibility of the phenomenon the graphs have been re-drawn in Figure 5 indicating in different colours the four plots on the same time scale.

It is fairly evident both the progressive increase of the breathing depth and the progressive slowdown of the respiratory acts after the treatment. Similar results were obtained on the other two volunteers as shown in the graphs of Figure 6 and in the Table 1 .

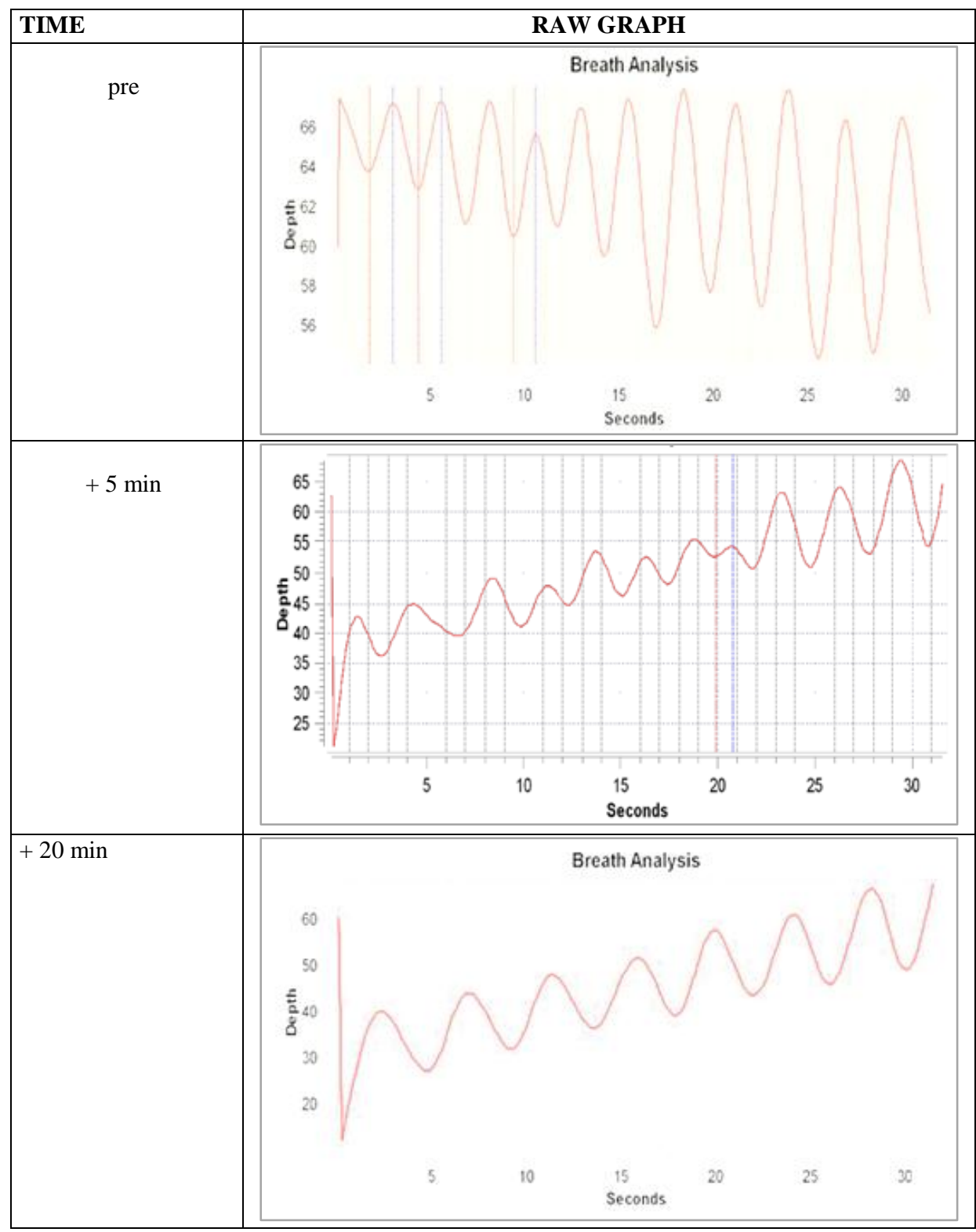




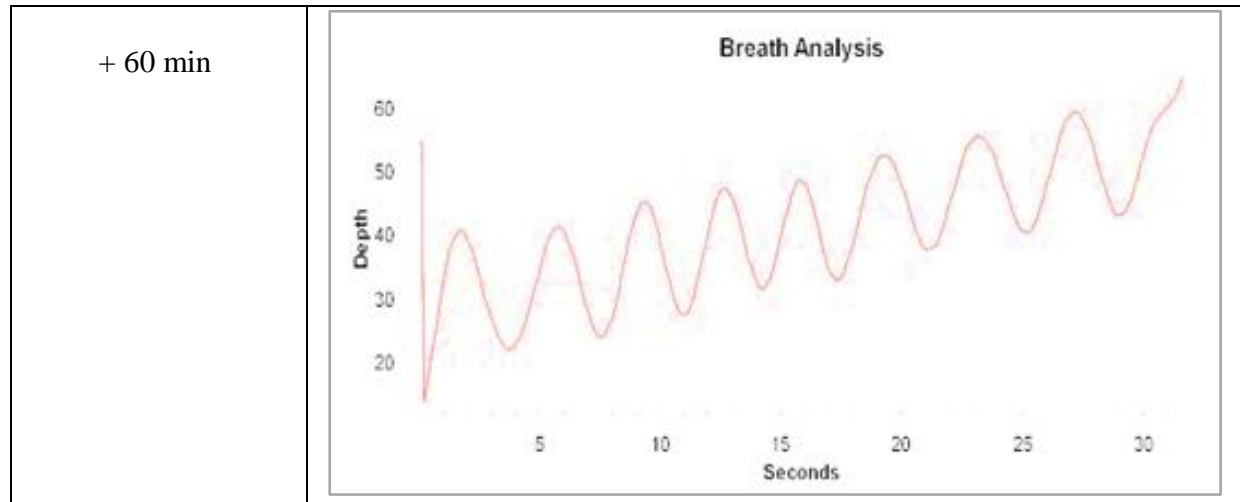

Figure 4: MV1 Raw graphs from the recording device.

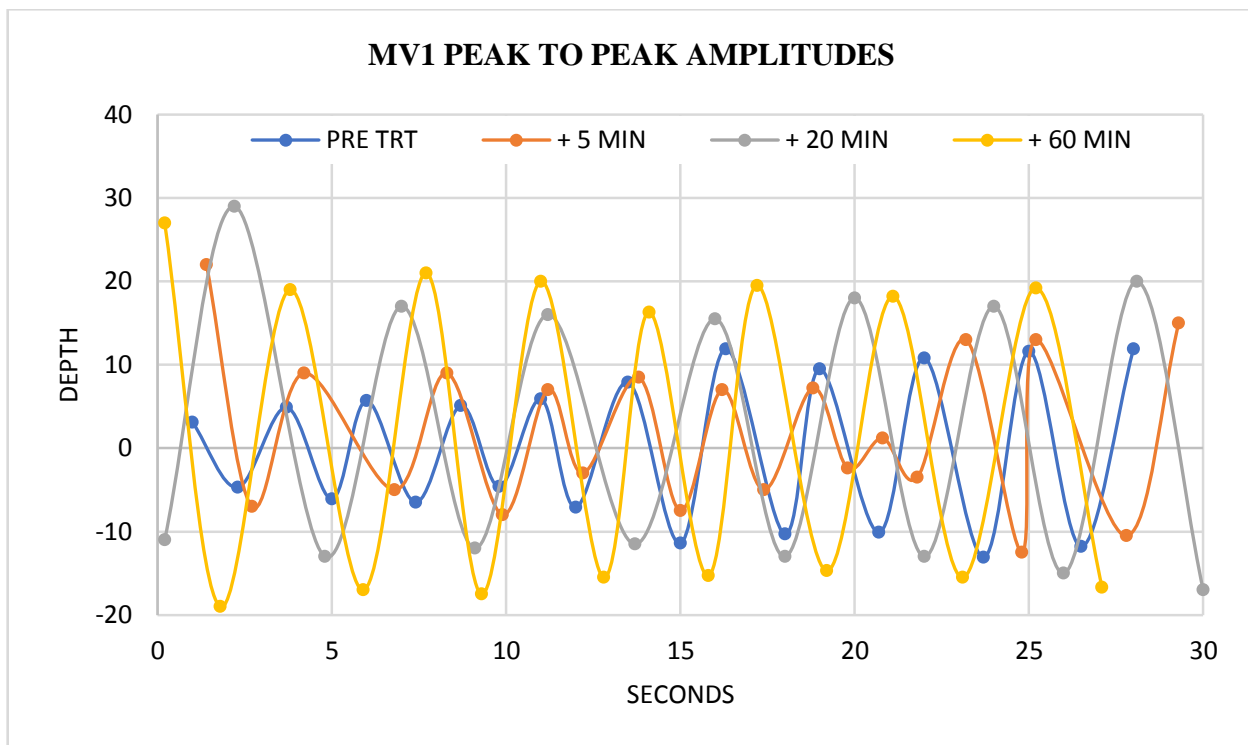

Figure 5: MV1 Peak-to-Peak breathing depth plotted on the same timescale
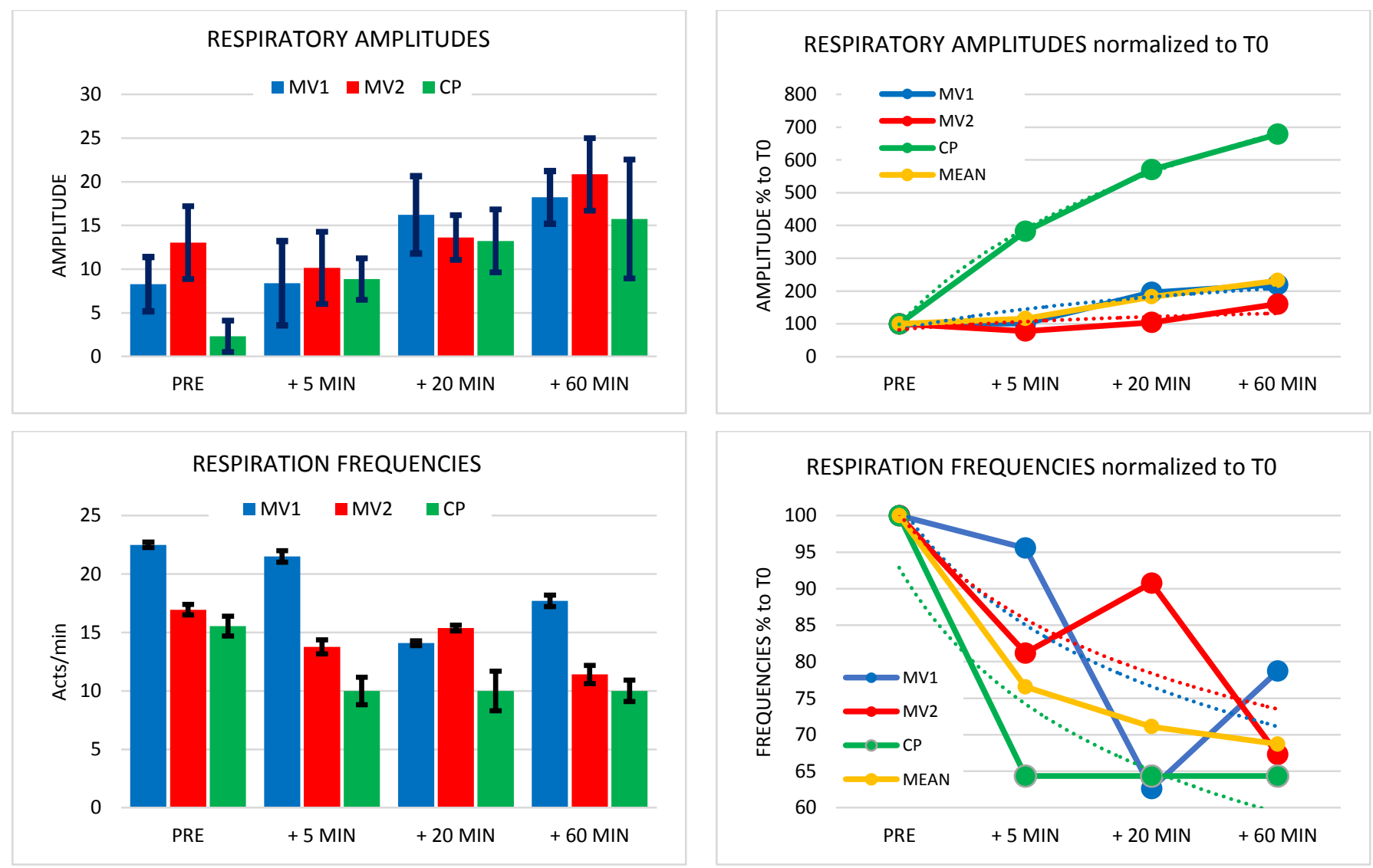

Figure 6: Results main graphs. Error bar on the left side graphs have the $\pm 1 \sigma$ value 
Table 1: Respiratory performances across the experiment

\begin{tabular}{|l|l|l|l|l|l|}
\hline & \multicolumn{2}{|l|}{ AMPLITUDES } & \multicolumn{2}{l|}{ INTERVALS } & FREQUENCIES \\
\cline { 2 - 6 } & Mean & Std Dev & Mean & Std Dev & /min \\
\hline PRE & 8,29 & 3,12 & 1,33 & 0,23 & 22,50 \\
\hline$+\mathbf{5}$ MIN & 8,40 & 4,82 & 1,40 & 0,49 & 21,50 \\
\hline$+\mathbf{2 0}$ MIN & 16,21 & 4,44 & 2,13 & 0,21 & 14,09 \\
\hline$+\mathbf{6 0}$ MIN & 18,21 & 3,01 & 1,69 & 0,49 & 17,71 \\
\hline
\end{tabular}

\section{Discussion}

It seems to be remarked the great benefit observed in the parameters of the subject $\mathrm{CP}$. The respiration frequency immediately slowed down while the depth of the respiratory act did progressively increase across the experiment. Overall, it should be remarked the rather rapid settlement of the beneficial effect within some 20 minutes from the treatment. Interestingly enough a reorganization phase of the respiratory activity is noticed immediately after the treatment. It can perhaps be a confirmation of the acupunctural effects on autonomic functions.

\section{Conclusion}

The test on three healthy subjects was undoubtedly showing a remarkable effect. It seems reasonable that an even greater result would be observed in post Covid rehabilitation. In fact, a recording made with the very same MIRA device on a SARS-2 patient (Figure 7) shows the presence of many respiratory anomalies mainly spasms - that we have observed to disappear almost immediately after the LU7 LieQue stimulation.

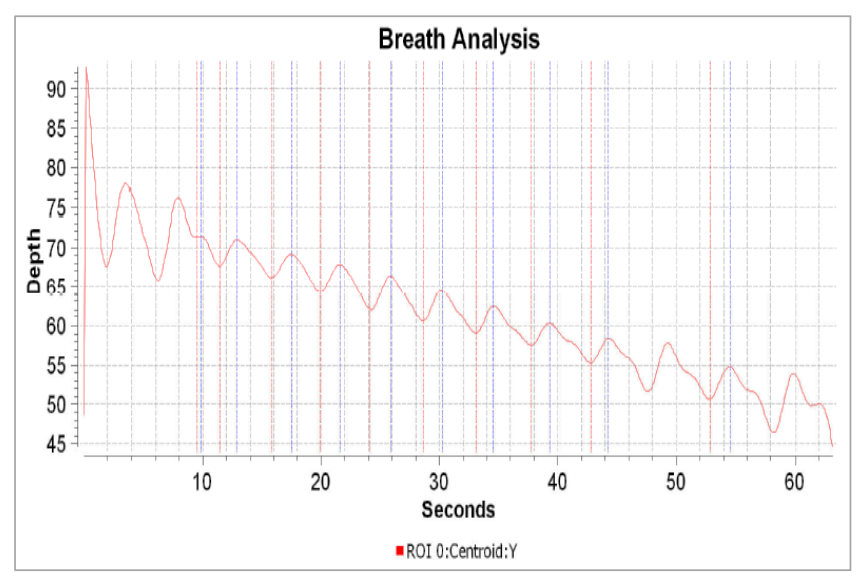

Figure 6: MIRA recorded respiratory activity of a SARS-2 affected patient. Please note the high number of functional respiratory anomalies

This test is somehow contributing a further confirmation of the acupuncture-like effect of Libralux stimulation. How the pulsating tiny flow of $650 \mathrm{~nm}$ photons can start stimulation along the Meridian channels is something worth further exploration but it could add some information to scientists studying the physiological action mechanisms of acupuncture ${ }^{[25-29]}$.

Getting back to clinical applications we believe that, taking also into account the almost negligible contra-indications to the kind of stimulation given by Libralux (Patients affected by neoplasia, pregnant women, subjects at risk of epileptic discharges, bearers of implanted electromedical devices of any kind) it could be worth performing a double-blind trial on post Covid-19 patients and on a control group of healthy, age matched, individuals, applying either Libralux or a sham laser stimulation. The application of the most usual respiratory tests (E.g. Borg scale on exhaustion ${ }^{[30]}$ ) that can be performed only in a clinical environment, would certainly provide further elements of evaluation.

On the other hand, expert acupuncturist could suggest a combination with other points such as, for ex-ample, BL 12 Fengmen and/or BL13 Feishu that are both known to be effective in pathologies of the lungs or ST36 Zusanlì and LI4 Hegu that are known to be effective in the promotion of muscle relax.

\section{Ethics approval and consent to participate}

The three volunteers subscribed their written consent MV, lent and operated the Libralux belonging to Oculistica Viva Eye clinic

\section{Conflicts of Interest}

Marzio Vanzini and Daniele Gullà declare the absence of any conflict of interests.

Michele Gallamini is a minority shareholder $(<1 \%)$ of Fremslife Srl producing Libralux.

\section{Funding Statement}

No funding was received

\section{Authors' contributions}

MV conceived and executed the experiment supporting MG in the conception of the manuscript. DG assisted as MIRA Camera operator and provided the recordings. MG drafted the manuscript and the figures. All authors read and approved the final manuscript.

\section{Acknowledgements}

DG, CEO and founder of Hyperspectral Imaging Co lent and operated the Mira device providing its output data.

\section{References}

[1] Barker-Davies RM, O'Sullivan O, Senaratne KPP, Baker P, Cranley M, Dharm-Datta S, Ellis H, Goodall D, Gough M, Lewis S, Norman J, Papadopoulou T, Roscoe D, Sherwood D, Turner P, Walker T, Mistlin A, Phillip R, Nicol AM, Bennett AN, Bahadur S. The Stanford Hall consensus statement for post-COVID-19 rehabilitation. $\mathrm{Br}$ J Sports Med. 2020 Aug;54(16):949-959. doi: 10.1136/bjsports-2020-102596. Epub 2020 May 31. PMID: 32475821; PMCID: PMC7418628.

[2] Demeco A, Marotta N, Barletta M, Pino I, Marinaro C, Petraroli A, Moggio L, Ammendolia A. Rehabilitation of patients post-COVID-19 infection: a literature review. J Int Med Res. 2020 Aug;48(8):300060520948382. doi: 
10.1177/0300060520948382. PMID: 32840156; PMCID: PMC7450453.

[3] Baratto L, Capra R, Farinelli M, Monteforte P, Morasso P, Rovetta G. A new type of very low-power modulated laser: soft-tissue changes induced in osteoarthritic patients revealed by sonography. Int J Clin Pharmacol Res. 2000;20(1-2):13-6

[4] Gallamini M. Treating balance disorders by ultra-lowlevel laser stimulation of acupoints. J Acupunct Meridian Stud. 2013;6:119e123.

[5] Monteforte P, Baratto L, Molfetta L, Rovetta G. Lowpower laser in osteoarthritis of the cervical spine. Int $\mathbf{J}$ Tissue Re-act. 2003;25(4):131-6

[6] Vanzini M, Gallamini M. Amblyopia: Can Laser Acupuncture be an Option? J Acupunct Meridian Stud. 2016 Oct;9(5):267-274

[7] Vanzini M, Gallamini M. Laser Acupuncture in OpenAngle Glaucoma Treatment A Retrospective Study of Eye Blood Flow. J Acupunct Meridian Stud. 2018 Dec 6. pii:S2005-2901(18)30052-9.

doi:10.1016/j.jams.2018.11.005

[8] Giuliani A, Fernandez M, Farinelli M, Baratto L, Capra R, Rovetta G, Monteforte P, Giardino L, Calzà L. Very low level la-ser therapy attenuates edema and pain in experimental models. Int J Tissue React. 2004;26(12):29-37

[9] Lorenzini L, Giuliani A, Capra R, Giardino L, Calza` L. Laser acupuncture using an uLLL device: effectiveness in rat mod-els of acute and persistent pain. SCIENCE Med an International Journal of Medical Sciences. $2010 ; 1$.

[10] Lorenzini L, Giuliani A, Giardino L, Calzà L. Laser acupuncture for acute inflammatory, visceral and neuropathic pain relief: An ex-perimental study in the laboratory rat. Res Vet Sci. 2010 Feb;88(1):159-65

[11] Giuliani A, Lorenzini L, Gallamini M, Massella A, Giardino L, Calzà L. Low infra red laser light irradiation on cultured neural cells: effects on mitochondria and cell viability after oxidative stress. BMC Complement Altern Med. 2009 Apr 15;9:8

[12] Giuliani A, Lorenzini L, Alessandri M, Torricella R, Baldassarro VA, Giardino L, Calzà L. In vitro exposure to very low-level laser modifies expression level of extracellular matrix protein RNAs and mitochondria dynamics in mouse em-bryonic fibroblasts. BMC Complement Altern Med. 2015 Mar 24;15:78

[13] Chin, P.; Fung, W. Probing the mystery of Chinese medicine meridian channels with special emphasis on the connec-tive tissue interstitial fluid system, mechanotransduction, cells durotaxis and mast cell degranulation. Chin. Med. 2009, 4, 10.

[14] Pollack, G.H. Cells, Gels and the Engines of Life; Ebner and Sons Publishers: Seattle, WA, USA, 10 March 2001.

[15] Baratto L, Calzà L, Capra R, Gallamini M, Giardino L, Giuliani A, Lorenzini L, Traverso S. Ultra-lowlevel laser therapy. La-sers Med Sci. 2011 Jan;26(1):103-12

[16] Evangelista L, De Meo B, Bernabei G, Belloni G, D'Angelo G, Vanzini M, Calzà L, Gallamini M. UltraLow-Level Laser Therapy and Acupuncture Libralux: What Is so Special? Medicines (Basel). 2019 Mar 14;6(1). pii: E40. doi:10.3390/medicines6010040
[17] Tunér, J.; Hode, L. Laser Therapy. Clinical Practice and Scientific Background; Prima Books AB: Grängesberg, Sweden, 2002

[18] Langevin HM, Yandow JA. Relationship of acupuncture points and meridians to connective tissue planes. Anat Rec. 2002 Dec 15;269(6):257-65. doi: 10.1002/ar.10185. PMID: 12467083.

[19] Huo R, Han SP, Liu FY, Shou XJ, Liu LY, Song TJ, Zhai FJ, Zhang R, Xing GG, Han JS. Responses of Primary Afferent Fibers to Acupuncture-Like Peripheral Stimulation at Different Frequencies: Characterization by Single-Unit Recording in Rats. Neurosci Bull. 2020 Aug;36(8):907-918. doi: 10.1007/s12264-020-00509-3. Epub 2020 May 11. PMID: 32394277; PMCID: PMC7410905.

[20] Jarmey, C.; Bouratinos, I. A Practical Guide to Acupoints, 2nd ed.; Lotus Publishing: Chichester, UK, 2018.

[21] Regional Office for the Western Pacific, WHO. Standard Acupuncture Nomenclature, 2nd ed.; World Health Organi-zation-Regional Office of Western Pacific Manila Philippines: Metro Manila, Philippines 1993.

[22] Sotte L., Minelli E., Giovanardi C., et al. Fondamenti di agopuntura e medicina cinese Ambrosiana Ed. Milano [Acu-puncture and Traditional Chinese Medicine fundamentals (Italian)] 2006 EAN: 9788832128703 ISBN: 8832128705

[23] Sotte L., Muccioli M., Diagnosi e terapia in agopuntura e medicina cinese. Trattamento delle principali malattie con agopuntura, auricoloterapia e dietetica cinese. Tecniche Nuove Ed. Milano [The treatment of main pathologies with acupuncture, auricolotherapy and dietary prescription according to the Traditional Chinese Medicine (Italian)] 1992 EAN: 9788870817553 ISBN: 8870817555

[24] Zhang B., Zhang K., Tang Q., Sun K., Han Z. Acupuncture for breathlessness in COVID-19: A protocol for systematic re-view and meta-analysis. Medicine (Baltimore) $2020 \quad$ Jul 2;99:e20701.doi:10.1097/MD.0000000000020701

[25] Langevin HM, Churcill DL, Cipolla MJ. Mechanical signaling through connective tissue: a mechanism for the therapeu-tic effect of acupuncture. FASB J. 2001 Oct; $15(12): 2275-82$

[26] Zhou W, Benharash P. Effects and mechanisms of acupuncture based on the principle of meridians. J Acupunct Me-ridian Stud. 2014 Aug;7(4):190-3. doi: 10.1016/j.jams.2014.02.007. Epub 2014 Jun 24. PMID: 25151452.

[27] Langevin HM, Churcill DL, Wu J, Badger GJ, Yandow JA, Fox JR, Krag MH. Evidence of connective tissue involvement in acupuncture. FASB J. 2002 Jun;16(8):872-4

[28] Zhang WB, Tian YY, Li H, Tian JH, Luo MF, Xu FL, Wang GJ, Huang T, Xu YH, Wang RH. A discovery of low hydraulic re-sistance channel along meridians. J Acupunct Meridian Stud. 2008 Sep;1(1):20-8

[29] Frederick H. Silver Mechanosensing and Mechanochemical Transduction in Extracellular Matrix Biological, Chemical, Engineering, and Physiological Aspects Springer US 2006 ISBN 978-0-387-25631-3 eBook ISBN 978-0-387-28176-6 DOI 10.1007/978-0387-28176-6 
[30] Kendrick KR, Baxi SC, Smith RM. Usefulness of the modified 0-10 Borg scale in assessing the degree of dyspnea in pa-tients with COPD and asthma. J Emerg
Nurs. 2000 Jun;26(3):216-22. doi: 10.1016/s00991767(00)90093-x. PMID: 10839848. 